\title{
PATEN UNTUK STUDI KASUS SMARTPHONE MOTOROLA LIPAT
}

\author{
Putra Rahmadi \\ 155100058, 785567837 \\ Fakultas Komputer \\ putrarahmadi.student@umitra.ac.id
}

\begin{abstract}
muncul sebuah brand legendaris yang kini telah dimiliki oleh Lenovo, Motorola yang membawa oase segar dalam persaingan teknologi yang sudah lama stagnan ini.paten ini sudah resmi diajukan pihak Motorola sejak September 2016. Sehingga, secara tidak langsung manufaktur yang berbasis di AS ini bisa digolongkan ke dalam jajaran brand gelombang awal yang memrakarsai konsep ponsel lipat.
\end{abstract}

Kata Kunci : paten smartphone lipat motorola.

\section{A. INTRODUCTION}

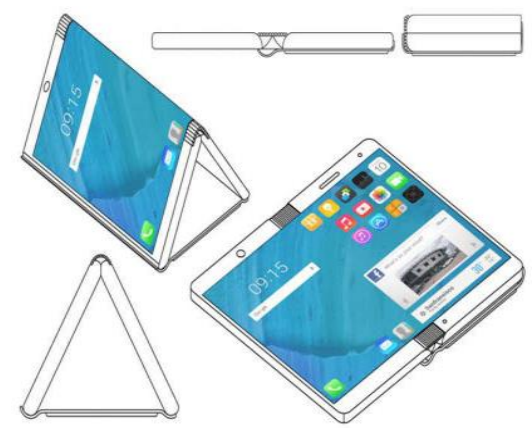

Perkembangan teknologi yang sangat pesat dalam industri smartphone menuntut para produsen untuk senantiasa selaras dan terus berpacu dengan terobosan-terobosan yang inovatif. Kamera ganda, sensor sidik jari, layar fullview, hingga asisten digital adalah segelintir contoh penemuan terkini yang dulunya mungkin tak pernah kita duga bisa hadir dalam sebuah ponsel pintar.

Salah satu inovasi berikutnya yang paling ditunggu-tunggu di industri ini adalah ponsel pintar yang dapat dilipat. Gagasan ini muncul atas keinginan para 
pengguna yang berharap bisa memiliki sebuah smartphone yang dapat dilipat sehingga menjadi lebih ringkas ketika disimpan di saku celana atau kemeja.

Motorola baru-baru ini mengajukan aplikasi paten yang menampilkan smartphone layar lipat dengan beberapa fitur menarik.

Permohonan paten telah diajukan oleh Motorola, baik di USPTO (Kantor Paten Amerika Serikat dan Merek Dagang) dan di WIPO (Organisasi Kekayaan Intelektual Dunia). Paten yang diterbitkan 10 Januari lalu itu ditemukan oleh tim laman Lets Go Digit paten untuk smarphone dan juga bisa menjadi tablet ini sudah dikantoi oleh pihak Motorola.

\section{B. CONTENT}

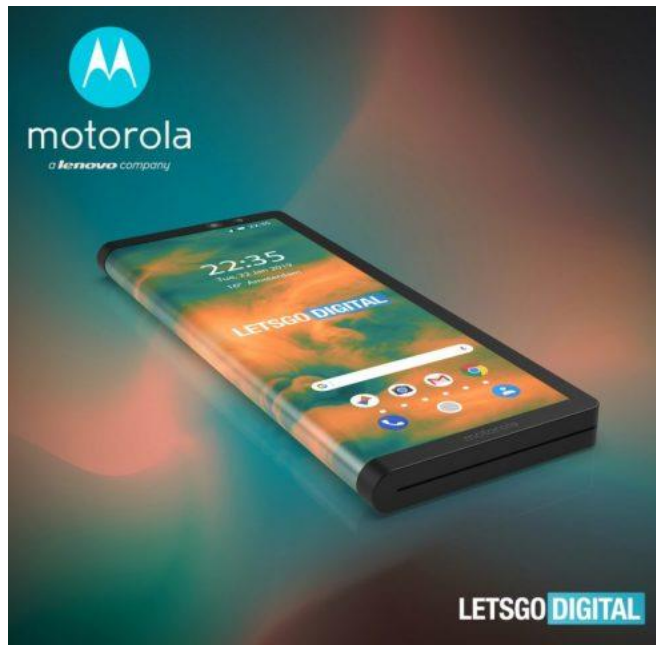

Di sisi lain, gagasan ini juga timbul berkat otak-otak kreatif para produsen yang berpendapat bahwa sebuah smartphone seharusnya bisa merangkap menjadi sebuah tablet.

Sejauh ini tidak sedikit vendor yang berupaya mewujudkan teknologi gemilang seperti itu, LG, Xiaomi, HUAWEI, bahkan Apple pun berlombalomba menciptakan smartphone lipat versi masingmasing. Samsung Galaxy X, dengan konsep serupa, dikabarkan siap melenggang awal tahun depan. Induk perusahaan nubia, ZTE, bahkan sudah lebih dulu mencuri start lewat produk Axon M. Meski hasil akhinya jauh dari harapan kita.

Dalam paten ini, perangkat yang disiapkan Motorola akan memungkinkan sebuah smartphone menjadi tablet ketika layar dibentangkan.

Perangkat ini sendiri memang merupakan inovasi yang canggih sehingga diperlukan pengembangan yang siap dari berbagai sisi sehingga Motorola mampu menyempurnakannya. Namun dilansir Phone Arena, Motorola tampaknya tak memiliki kemungkinan untuk menghadirkan smartphone yang mampu menjadi tablet.

Dari paten yang terungkap, engsel yang berada di tengah perangkat tampak seperti engsel biasa. Komponen itu bahkan mirip dengan yang ditemukan pada ZTE Axon M yang hadir dengan layar ganda, bukan dipadukan sebagaimana tablet. Pengajuan paten itu sendiri berisikan informasi 
terkait cover yang seharusnya tidak hanya melindungi perangkat, namun juga bertindak sebagai pengisi daya nirkabel saat pengguna membutuhkannya. Selebihnya belum jelas bagaimana konsep perangkat yang ada dalam paten itu. Yang jelas paten ini menunjukkan ambisi Motorola untuk turut andil dalam inovasi smartphone yang kini juga tengah dikembangkan oleh banyak vendor.

Tak hanya Motorola, beberapa vendor juga memiliki minat untuk mengembangkan smartphone berlayar lipat. Samsung bahkan telah mengumbar rencananya untuk handset tersebut. Mulanya raksasa teknologi asal Korea Selatan itu akan merilis smartphone lipat pada 2018.

Namun kemudian DJ Koh, bos Samsung Mobile menyatakan smartphone lipat yang disebut Galaxy $X$ tersebut akan menampakkan wujudnya pada 2019. Demikian dilansir Phone Arena.

\section{CONCLUSION}

Perangkat ini dapat dibentangkan menjadi sebuah tablet atau ditekuk untuk beralih fungsi menjadi smartphone. Terlihat pula rancangan sebuah case yang dapat digunakan sebagai penyangga, pelindung layar, hingga pengisi daya nirkabel bagi perangkat ini. Jika itu benar, paten ini sekaligus akan mengatasi masalah substansial terkait kesulitan para produsen untuk menghadirkan material layar smartphone yang bersifat fleksibel. Gambar desain yang terkandung dalam paten juga menggambarkan mode interaksi lainnya melalui berbagai gerakan. Contohnya dengan sentuhan sederhana, tekanan, cubitan, dan sebagainya.

\section{DISCUSSION}

paten pada dasarnya adalah perangkat yang setelah dilipat dapat dioperasikan pada satu layar dengan hasil yang ditampilkan di layar lainnya. Kedengarannya rumit dan berlawanan dengan intuisi, tapi coba kita bayangkan menggulir di layar belakang dengan jari Anda dan konten di layar depan bergerak. Ada juga pembicaraan tentang keberadaan dua kamera untuk pendeteksi wajah pengguna agar perangkat memahami separuh tampilan yang dilihat oleh pengguna dan mana yang tidak.

\section{E. REFERENCE}

[1] O. M. Febriani and A. S. Putra, "Sistem Informasi Monitoring Inventori Barang Pada Balai Riset Standardisasi Industri Bandar Lampung," J. Inform., vol. 13, no. 1, pp. 90-98, 2014.

[2] A. S. Putra, "Paperplain: Execution Fundamental Create Application With Borland 
Delphi 7.0 University Of Mitra Indonesia," 2018.

[3] A. S. Putra, "2018 Artikel Struktur Data, Audit Dan Jaringan Komputer," 2018.

[4] A. S. Putra, "ALIAS MANAGER USED IN DATABASE DESKTOP STUDI CASE DB DEMOS."

A. S. Putra, "COMPREHENSIVE SET OF PROFESSIONAL FOR DISTRIBUTE COMPUTING."

[6] A. S. Putra, "DATA ORIENTED RECOGNITION IN BORLAND DELPHI 7.0."

[7] A. S. Putra, "EMBARCADERO DELPHI XE 2 IN GPUPOWERED FIREMONKEY APPLICATION."

[8] A. S. Putra, "HAK ATAS KEKAYAAN INTELEKTUAL DALAM DUNIA TEKNOLOGY BERBASIS REVOLUSI INDUSTRI 4.0."

[9] A. S. Putra, "IMPLEMENTASI PERATURAN

PERUNDANGAN UU. NO 31

TAHUN 2000 TENTANG DESAIN INDUSTRI BERBASIS INFORMATION TECHNOLOGY."

[10] A. S. Putra, "IMPLEMENTATION OF PARADOX DBASE.'

A. S. Putra, "IMPLEMENTATION OF

TRADE SECRET CASE STUDY SAMSUNG MOBILE PHONE."

[12] A. S. Putra, "IMPLEMENTATION

PATENT FOR APPLICATION WEB BASED CASE STUDI WWW. PUBLIKLAMPUNG.
COM."

[13] A.

"IMPLEMENTATION

SYSTEM FIRST TO INVENT

IN DIGITALLY INDUSTRY."

[14] A. S. Putra, "MANUAL REPORT \& INTEGRATED DEVELOPMENT

ENVIRONMENT BORLAND DELPHI 7.0."

[15] A. S. Putra, "PATENT AS RELEVAN SUPPORT RESEARCH."

[16] A. S. Putra, "PATENT FOR RESEARCH STUDY CASE OF APPLE. Inc."

[17] A. S. Putra, "PATENT PROTECTION FOR APPLICATION INVENT."

[18] A. S. Putra, "QUICK REPORT IN PROPERTY PROGRAMMING."

[19] A. S. Putra, "REVIEW CIRCUIT LAYOUT COMPONENT

REQUIREMENT ON ASUS NOTEBOOK."

[20] A. S. Putra, "REVIEW TRADEMARK PATENT FOR INDUSTRIAL

TECHNOLOGY BASED 4.0."

[21] A. S. Putra, "TOOLBAR COMPONENT PALLETTE IN OBJECT ORIENTED PROGRAMMING."

[22] A. S. Putra, "WORKING DIRECTORY SET FOR PARADOX 7."

[23] A. S. Putra, "ZQUERY CONNECTION

IMPLEMENTED

PROGRAMMING STUDI CASE PT. BANK BCA Tbk."

[24] A. S. Putra, D. R. Aryanti, and I. Hartati, "Metode SAW 
(Simple Additive Weighting) sebagai Sistem Pendukung Keputusan Guru Berprestasi (Studi Kasus: SMK Global Surya)," in Prosiding Seminar Nasional Darmajaya, 2018, vol. 1, no. 1, pp. 85-97.

[25] A. S. Putra and O. M. Febriani, "Knowledge Management Online Application in PDAM Lampung Province," in Prosiding International conference on Information Technology and Business (ICITB), 2018, pp. 181-187.

[26] A. S. Putra, O. M. Febriani, and B. Bachry, "Implementasi Genetic Fuzzy System Untuk Mengidentifikasi Hasil Curian Kendaraan Bermotor Di Polda Lampung," SIMADA (Jurnal Sist. Inf. dan Manaj. Basis Data), vol. 1, no. 1, pp. 21-30, 2018.

[27] A. S. Putra, H. Sukri, and K. Zuhri, "Sistem Monitoring Realtime Jaringan Irigasi Desa (JIDES) Dengan Konsep Jaringan Sensor Nirkabel," IJEIS (Indonesian J. Electron. Instrum. Syst., vol. 8, no. 2, pp. 221-232.

[28] D. P. Sari, O. M. Febriani, and A. S. Putra, "Perancangan Sistem Informasi SDM Berprestasi pada SD Global Surya," in Prosiding Seminar Nasional Darmajaya, 2018, vol. 1, no. 1, pp. 289-294. 